\title{
Thermal conductivity variation in uranium dioxide with gadolinia additions
}

Qin, Meng; Middleburgh, Simon; Cooper, M. W. D.; Rushton, Michael; Puide, Mattias; Kuo, E. Y.; Grimes, Robin W.; Lumpkin, Gregory R.

\section{Journal of Nuclear Materials}

DOI:

https://doi.org/10.1016/j.jnucmat.2020.152258

Published: 01/11/2020

Peer reviewed version

Cyswllt i'r cyhoeddiad / Link to publication

Dyfyniad o'r fersiwn a gyhoeddwyd / Citation for published version (APA):

Qin, M., Middleburgh, S., Cooper, M. W. D., Rushton, M., Puide, M., Kuo, E. Y., Grimes, R. W., \& Lumpkin, G. R. (2020). Thermal conductivity variation in uranium dioxide with gadolinia additions. Journal of Nuclear Materials, 540, [152258].

https://doi.org/10.1016/j.jnucmat.2020.152258

Hawliau Cyffredinol / General rights

Copyright and moral rights for the publications made accessible in the public portal are retained by the authors and/or other copyright owners and it is a condition of accessing publications that users recognise and abide by the legal requirements associated with these rights.

- Users may download and print one copy of any publication from the public portal for the purpose of private study or research.

- You may not further distribute the material or use it for any profit-making activity or commercial gain

- You may freely distribute the URL identifying the publication in the public portal ?

Take down policy

If you believe that this document breaches copyright please contact us providing details, and we will remove access to the work immediately and investigate your claim. 


\title{
Thermal conductivity variation with $\mathrm{Gd}$ accommodation in Gd-doped $\mathrm{UO}_{2}$ using NEMD method
}

\author{
M.J. Qin ${ }^{a, *}$, S.C. Middleburgh ${ }^{\text {b,c }}$, M.W.D. Cooper ${ }^{\mathrm{d}}$, M.J.D. Rushton ${ }^{\mathrm{c}, \mathrm{e}}$, M.

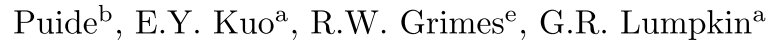 \\ ${ }^{a}$ Australian Nuclear Science and Technology Organisation, Lucas Heights, New South \\ Wales, Australia \\ ${ }^{b}$ Westinghouse Electric Sweden, Bränslegatan 1, 72136 Västerås, Sweden \\ ${ }^{c}$ Nuclear Futures Institute, Bangor University, Bangor, LL57 1UT, U.K. \\ ${ }^{d}$ Materials Science and Technology Division, Los Alamos National Laboratory, PO Box \\ 1663, Los Alamos, NM 87545, U.S.A. \\ ${ }^{e}$ Department of Materials, Imperial College London, South Kensington, London, U.K.
}

\begin{abstract}
By combining experimental observations on Gd doped fuel with a theoretical understanding, the variation in thermal conductivity with Gd concentration and accommodation mechanism has been modelled. Four types of Gd accommodation mechanisms have been studied. In $\mathrm{UO}_{2-x}$, isolated substitutional $\mathrm{Gd}^{3+}$ ions are compensated by oxygen vacancies and $\left\{2 \mathrm{Gd}_{\mathrm{U}}^{\prime}: \mathrm{V}_{\mathrm{O}}\right\}^{\times}$defect clusters. In $\mathrm{UO}_{2}$, isolated substitutional $\mathrm{Gd}^{3+}$ ions are compensated by $\mathrm{U}^{5+}$ ions and $\left\{\mathrm{Gd}_{\mathrm{U}}^{\prime}: \mathrm{U}_{\mathrm{U}}\right\}^{\times}$defect clusters. The results indicate that defect clusters can be considered as less effective phonon scatterers and therefore result in less thermal conductivity degradation. The thermal conductivity predicted for $\mathrm{UO}_{2}$ with $\left\{\mathrm{Gd}_{\mathrm{U}}^{\prime}: \mathrm{U}_{\mathrm{U}}\right\}^{\times}$defect clusters is in good agreement with experimental data for $\mathrm{UO}_{2}$ with $5 \mathrm{wt} \% \mathrm{Gd}_{2} \mathrm{O}_{3}$. This supports the previous theoretical results that $\mathrm{Gd}$ is accommodated through defect clusters $\left\{\mathrm{Gd}_{\mathrm{U}}^{\prime}: \mathrm{U}_{\mathrm{U}}\right\}^{\times}$in $\mathrm{UO}_{2}$ in the presence of excess oxygen.
\end{abstract}

Keywords: $\mathrm{Gd}_{2} \mathrm{O}_{3}$-doped $\mathrm{UO}_{2}$, Thermal conductivity, Gadolinium accommodation mechanism, Molecular dynamics simulations

\footnotetext{
* Corresponding author

Email address: mqi@ansto.gov.au (M.J. Qin)
} 


\section{Introduction}

Neutron poisons are commonly added to nuclear fuels to limit the initial reactivity in specified pellets/rods identified within the reactor core at the beginning of the operational cycle. This limiting of reactivity has a beneficial effect on the overall lifetime of the core by enabling the use of higher enrichment fuel, providing more fissionable material that extends useful residency of the fuel. The effectiveness of burnable poisons purposefully decreases over time as the neutron absorbing elements are transmuted into elements with lower neutron cross sections (i.e. are used up). The burnable poison can take the form of pins or plates in the fuel assembly or as an additive to the fuel pellet itself. Boron [1], erbium [2] and gadolinium [3] have all been chosen as burnable absorbers in the past: boron is used out of the pellet either as a pellet coating (e.g. $\mathrm{ZrB}_{2}$ [1]) or within the assembly, whilst gadolinium and erbium oxide are used as fuel additives, and create some interesting crystal-chemical and energetic issues with regard to the initial impurity accomodation mechanisms and modifications to the fuel during burn-up.

$\mathrm{Gd}$ is added in fuel as a sesquioxide (i.e. $\mathrm{Gd}_{2} \mathrm{O}_{3}$ ) $[4,5]$. Past work, both experimental and theoretical, has shown that trivalent oxides can be accommodated in large molar volumes within the $\mathrm{UO}_{2}$ crystal lattice [6]. The accommodation mechanism of the sesquioxides in $\mathrm{UO}_{2}$ varies significantly with the amount of oxygen available during the solution reaction: in $\mathrm{UO}_{2-x}$ in the absence of excess oxygen, $\mathrm{Gd}^{3+}$ is accommodated by forming a charge compensating oxygen vacancy for every two substitutional Gd ions, resulting in $(\mathrm{U}, \mathrm{Gd}) \mathrm{O}_{2-x}[7]$. In $\mathrm{UO}_{2+x}$ where excess oxygen is present, substitutional $\mathrm{Gd}^{3+}$ ions are charge compensated by $\mathrm{U}^{5+}$ cations. The solubility of $\mathrm{Gd}$ or $\mathrm{Er}$ in the presence of excess oxygen is limited by the amount of excess oxygen, whereas in the absence of excess oxygen, solubility is a function of temperature [7].

The thermal conductivity of $\mathrm{UO}_{2}$ is a key property to understand, for the safe and efficient operation of nuclear fuel $[8,9,10]$. Each fission event produces heat, which is transported through the fuel into the cooling fluid of the power 
reactor. Past theoretical work has predicted that temperature [11, 12], radiation damage induced defects [13] and secondary phases [14] have major impacts on the fuel's thermal conductivity.

Any degradation in the thermal conductivity of the fuel will have a significant 35 impact on fuel performance, increasing the centre line temperature in a fuel pellet at the beginning of life and into operation compared to a standard $\mathrm{UO}_{2}$ pellet. This will have knock-on effects on fission gas release and fission product behaviour. Additionally, not only will the margin to melting of the fuel be reduced as a consequence of the addition of Gd, thereby raising the centre-line

40 temperature, but also by the lower melting point of $\mathrm{UO}_{2}-\mathrm{Gd}_{2} \mathrm{O}_{3}$ solid solutions compared to $\mathrm{UO}_{2}[15]$.

Past experimental work has measured the change in thermal conductivity with Gd content $[16,17,18,19,20,21,22,23]$. The thermal conductivity was observed to decrease with increasing Gd content at relatively low temperatures, but was independent of the Gd content at temperatures close to $2000 \mathrm{~K}$ [19]. Simulated burn-up has been taken into account in $\mathrm{UO}_{2}$ and (U,Gd) $\mathrm{O}_{2}$ using soluble fission product elements ( $\mathrm{Sr}, \mathrm{Zr}, \mathrm{Y}, \mathrm{La}, \mathrm{Ce}, \mathrm{Nd}$ ) [20]. The thermal conductivity was observed to decrease with an increase in the total amount of soluble elements at low temperature, but was almost independent of soluble 50 fission element content at higher temperature [20]. Amaya et al. investigated the effect of hyper-stoichiometry on the thermal conductivity of $10 \mathrm{wt} \% \mathrm{Gd}_{2} \mathrm{O}_{3}$ doped $\mathrm{UO}_{2+x}$, and observed degradation in thermal conductivity with increasing hyper-stoichiometry $[17,18]$. The thermal conductivity of irradiated (U,Gd) $\mathrm{O}_{2}$ has been studied by Amaya et al. [16] and Minato et al. [23]; the thermal conductivity decreased with irradiation, and partly recovered after the thermal diffusivity measurements at high temperatures. The recovery of the thermal conductivity was due to the recovery of the irradiation-induced point defects during the measurements. These experimental observations were explained in terms of phonon-phonon scattering and phonon-point defect scattering [19], as 60 well as phonon-extended defect scattering [23].

However, the link between the change in thermal conductivity and the spe- 
cific defect accommodation mechanism has not been considered. There has been recent work to study the nature of point defects in non-stoichiometric $\mathrm{UO}_{2}$ [24]. Due to the requirement for large supercells and associated computational costs, it is still impractical to use first-principle calculations to investigate the lattice thermal conductivity of actinide mixtures (or $\mathrm{UO}_{2}$ with additives) with point defects. In this work, the impact of $\mathrm{Gd}_{2} \mathrm{O}_{3}$ doping on the thermal conductivity of $\mathrm{UO}_{2}$ due to accommodation by oxygen vacancies and $\mathrm{U}^{5+}$ cations is explored using non-equilibrium molecular dynamics simulations and compared to experimentally obtained data.

\section{Methodology}

\subsection{Interatomic potentials}

The $\mathrm{UO}_{2}$ potential form used here [25] combines the Buckingham interatomic potential with a many body embedded atom (EAM) term, so that the energy of an ion $i, E_{i}\left(r_{i j}\right)$, is given by

$$
E_{i}\left(r_{i j}\right)=\frac{1}{2} \sum_{j} \phi_{\alpha \beta}\left(r_{i j}\right)-G_{\alpha} \sqrt{\sum_{j} \frac{n_{\beta}}{r_{i j}^{8}}},
$$

where $\phi_{\alpha \beta}\left(r_{i j}\right)$ is the pair-wise interaction between two atoms $i$ and $j$, separated by $r_{i j}$, and $G_{\alpha}, n_{\beta}$ are parameters associated with the many-body term. The pair-wise interaction has both long-range electrostatic, $\phi_{C}\left(r_{i j}\right)$, and shortrange contributions. The latter are described using Morse, $\phi_{M}\left(r_{i j}\right)$, and Buck-

80 ingham, $\phi_{B}\left(r_{i j}\right)$, potential forms, where $\alpha$ and $\beta$ are used to label the species of atom $i$ and atom $j$, respectively:

$$
\begin{gathered}
\phi_{\alpha \beta}\left(r_{i j}\right)=\phi_{C}\left(r_{i j}\right)+\phi_{B}\left(r_{i j}\right)+\phi_{M}\left(r_{i j}\right) \\
\phi_{C}\left(r_{i j}\right)=\frac{q_{\alpha} q_{\beta}}{4 \pi \epsilon_{0} r_{i j}} \\
\phi_{B}\left(r_{i j}\right)=A_{\alpha \beta} \exp \left(-\frac{r_{i j}}{\rho_{\alpha \beta}}\right)-\frac{C_{\alpha \beta}}{r_{i j}^{6}}
\end{gathered}
$$


Table 1: Parameters for the pairwise interactions described by Eq. (1-5) [25, 27, 28].

\begin{tabular}{lcccccc}
\hline \hline \multirow{2}{*}{ Interaction } & \multicolumn{3}{c}{$\Phi_{B}\left(r_{i j}\right)$} & \multicolumn{3}{c}{$\Phi_{M}\left(r_{i j}\right)$} \\
\cline { 2 - 7 }$\alpha-\beta$ & $A_{\alpha \beta}(\mathrm{eV})$ & $\rho_{\alpha \beta}(\AA)$ & $C_{\alpha \beta}\left(\mathrm{eV} \AA^{6}\right)$ & $D_{\alpha \beta}(\mathrm{eV})$ & $\gamma_{\alpha \beta}\left(\AA^{-1}\right)$ & $r_{0}(\AA)$ \\
\hline $\mathrm{U}^{5+}-\mathrm{O}^{2-}$ & 1155.631 & 0.3465 & 0 & 1.9317 & 2.0528 & 2.0709 \\
$\mathrm{U}^{5+}-\mathrm{U}^{5+}$ & 18600 & 0.2429 & 0 & - & - & - \\
$\mathrm{U}^{5+}-\mathrm{U}^{4+}$ & 18600 & 0.2583 & 0 & - & - & - \\
$\mathrm{U}^{4+}-\mathrm{O}^{2-}$ & 448.7789 & 0.3878 & 0 & 0.6608 & 2.0582 & 2.3805 \\
$\mathrm{U}^{4+}-\mathrm{U}^{4+}$ & 18600 & 0.2747 & 0 & - & - & - \\
$\mathrm{Gd}^{3+}-\mathrm{O}^{2-}$ & 37562.031 & 0.1938 & 0 & - & - & - \\
$\mathrm{O}^{2-}-\mathrm{O}^{2-}$ & 830.2834 & 0.3529 & 3.8844 & - & - & - \\
\hline \hline
\end{tabular}

$$
\phi_{M}\left(r_{i j}\right)=D_{\alpha \beta}\left[\exp \left(-2 \gamma_{\alpha \beta}\left(r_{i j}-r_{\alpha \beta}^{0}\right)\right)-2 \exp \left(-\gamma_{\alpha \beta}\left(r_{i j}-r_{\alpha \beta}^{0}\right)\right)\right]
$$

where $A_{\alpha \beta}, \rho_{\alpha \beta}, C_{\alpha \beta}, D_{\alpha \beta}, \gamma_{\alpha \beta}$, and $r_{\alpha \beta}^{0}$ are empirical parameters describing the Buckingham and Morse potentials between atom $i$ and atom $j$. The total charge of the ions $q_{\alpha}=Z_{\alpha}^{\text {eff }}|e|$ describes the Coulombic contribution $\left(Z_{\alpha}^{\text {eff }}=2.2208\right.$

85 for $\mathrm{U}^{4+}$ ions, $Z_{\alpha}^{\text {eff }}=2.7760$ for $\mathrm{U}^{5+}$ ions, $Z_{\alpha}^{\text {eff }}=1.6656$ for $\mathrm{Gd}^{3+}$ ions, and $Z_{\alpha}^{e f f}=-1.1104$ for oxygen anions). The pairwise potential parameters are summarised in Table 1.

The second term in equation (1) uses the EAM model to introduce a subtle many-body perturbation to the more dominant pairwise interactions [25] with potential parameters reported in Table 2. This potential model has already proven to be excellent for modelling thermal and mechanical properties of $\mathrm{UO}_{2}$ $[25,13]$. Additional developments of a Gd-O potential by Rushton and Chroneos [26] and $\mathrm{U}^{5+}$ potential by Liu et al. [27, 28] are incorporated in this work.

\subsection{Details of the simulation}

Five supercell models $\left(\mathrm{UO}_{2}\right.$, U4-random, U4-bound, U5-random and U5bound), representing different $\mathrm{Gd}$ accommodation mechanisms, were used to 

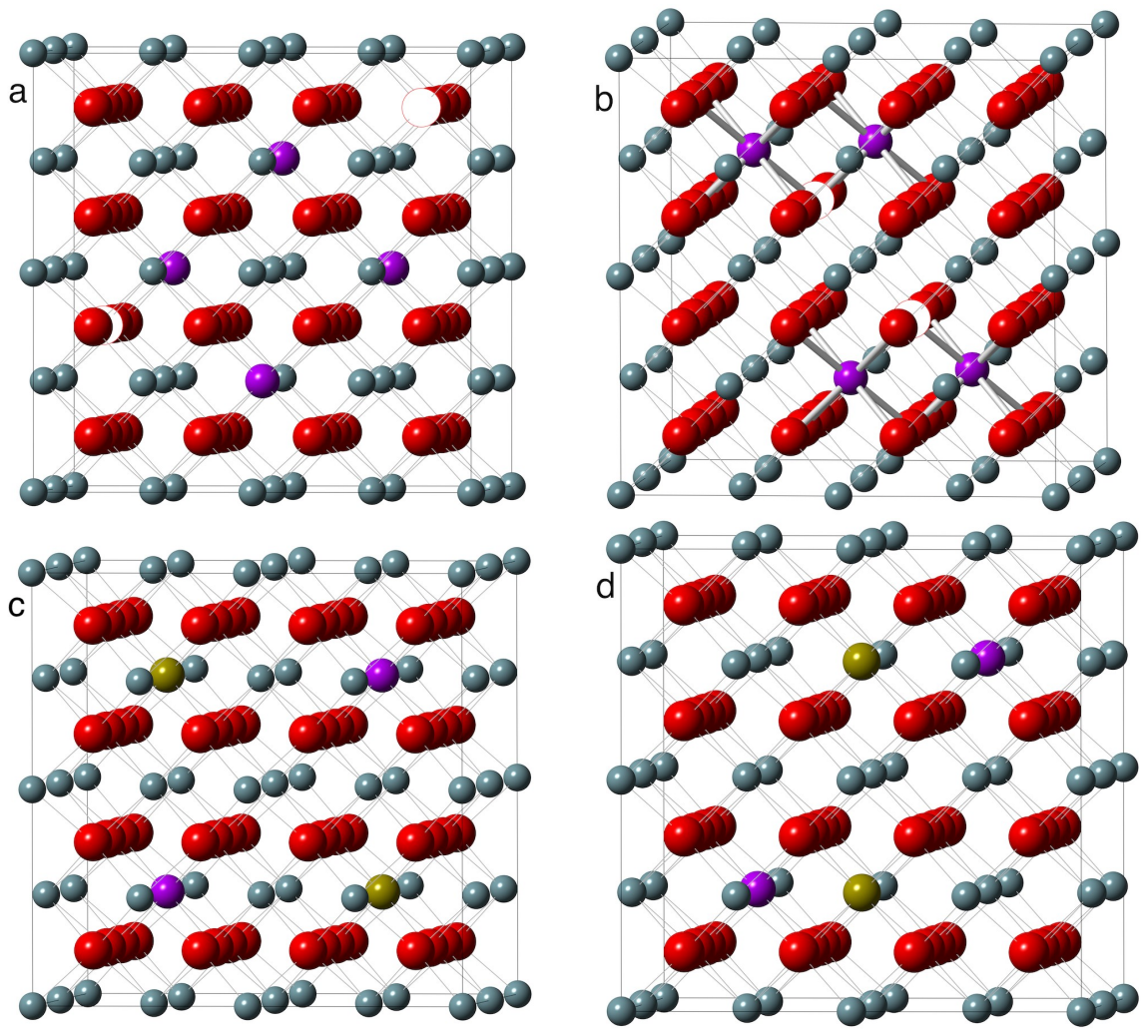

Figure 1: Schematic diagram of a $2 \times 2 \times 2$ supercell of $\mathrm{UO}_{2}$ doped with $\mathrm{Gd}_{2} \mathrm{O}_{3}$, showing different Gd accommodation mechanisms: (a) isolated $\mathrm{Gd}^{3+}$ ions in $\mathrm{UO}_{2-x}$ (U4-random), (b) $\left\{2 \mathrm{Gd}_{\mathrm{U}}^{\prime}: \mathrm{V}_{\mathrm{O}}\right\}^{\times}$defect clusters in $\mathrm{UO}_{2-x}$ (U4-bound), (c) isolated $\mathrm{Gd}^{3+}$ ions in $\mathrm{UO}_{2}$ (U5-random), (d) $\left\{\mathrm{Gd}_{\mathrm{U}}^{\prime}: \mathrm{U}_{\mathrm{U}}\right\}^{\times}$defect clusters in $\mathrm{UO}_{2}$ (U5-bound). Oxygen is represented as red, $\mathrm{U}^{4+}$ - grey-blue, oxygen vacancy - hollow, $\mathrm{Gd}$ - purple, $\mathrm{U}^{5+}$ - gold. 
investigate the effects on the thermal conductivity of $\mathrm{UO}_{2}$. U4-random represents isolated $\mathrm{Gd}^{3+}$ substitutional defects in $\mathrm{UO}_{2-x}$. It was generated from $\mathrm{UO}_{2}$ by randomly removing $n \mathrm{O}^{2-}$ atoms (leaving behind $n$ oxygen vacancies) and randomly replacing $2 n \mathrm{U}^{4+}$ atoms with $\mathrm{Gd}^{3+}$ atoms (the value of $n$ depends on the doping level). U4-bound represents $\left\{2 \mathrm{Gd}_{\mathrm{U}}^{\prime}: \mathrm{V}_{\mathrm{O}}\right\}^{\times}$defect clusters in $\mathrm{UO}_{2-x}$ and was generated from $\mathrm{UO}_{2}$ by randomly removing $n \mathrm{O}^{2-}$ atoms but then replacing the two nearest $\mathrm{U}^{4+}$ atoms bounding each removed $\mathrm{O}^{2-}$ atom with two $\mathrm{Gd}^{3+}$ atoms. Similarly, U5-random also represents isolated $\mathrm{Gd}^{3+}$ substitutional atoms in $\mathrm{UO}_{2}$, and was generated from $\mathrm{UO}_{2}$ by randomly replacing $n \mathrm{U}^{4+}$ atoms with $\mathrm{Gd}^{3+}$ atoms and then randomly replacing $n \mathrm{U}^{4+}$ atoms with $\mathrm{U}^{5+}$ atoms (i.e. charge compensation by $\mathrm{U}^{5+}$ not oxygen vacancy). U5-bound represents $\left\{\mathrm{Gd}_{\mathrm{U}}^{\prime}: \mathrm{U}_{\mathrm{U}}\right\}^{\times}$defect clusters in the $\mathrm{UO}_{2}$ lattice. It was generated from $\mathrm{UO}_{2}$ by randomly replacing $n \mathrm{U}^{4+}$ atoms with $\mathrm{U}^{5+}$ atoms and then replacing randomly one of the nearest neighbour $\mathrm{U}^{4+}$ atoms of each $\mathrm{U}^{5+}$ atom with a $\mathrm{Gd}^{3+}$ atom. Figure 1 shows the Gd accommodation mechanisms using (conveniently small) $2 \times 2 \times 2$ supercells of $\mathrm{UO}_{2}$ doped with $\mathrm{Gd}_{2} \mathrm{O}_{3}$.

The Gd-O potential was originally developed for rare-earth doped $\mathrm{CeO}_{2}$. To verify its application in the $\mathrm{UO}_{2}$ system, the lattice parameters of the Gddoped $\mathrm{UO}_{2}$ as a function of the Gd content have been calculated as shown in Fig. 2. The lattice parameter of $\mathrm{Gd}$ doped $\mathrm{UO}_{2}$ has been discussed previously with two possible charge compensation mechanisms as the Gd content increases: the creation of the smaller $\mathrm{U}^{5+}$ cation and the formation of oxygen vacancies $[29,34,35]$. The smaller $\mathrm{U}^{5+}$ cation results in a contraction of the lattice, while the oxygen vacancies were reported to be larger than the $\mathrm{O}^{2-}$ ion [34]. The decreasing lattice parameters of U5-bound and U5-random (no oxygen vacancies) with Gd content are consistent with experimental results from Liu et al. [29], Kim et al. [35], Baena et al. [30], and Durazzo et al. [31]. This is due to the smaller $\mathrm{U}^{5+}$ cation as compared to the $\mathrm{U}^{4+}$ cation. For hypo-stoichiometric ${ }_{125}(\mathrm{U}, \mathrm{Gd}) \mathrm{O}_{2}$ solid solutions of $\left(\mathrm{U}_{1-2 x+2 y}^{4+} \mathrm{U}_{x-2 y}^{5+} \mathrm{Gd}_{x}^{3+}\right) \mathrm{O}_{2-y}$ type, it was shown that the lattice parameter increases with a decrease in the $\mathrm{O} / \mathrm{M}$ ratio or an increase of oxygen vacancy concentration at constant concentration of Gd [34]. Ohmichi 


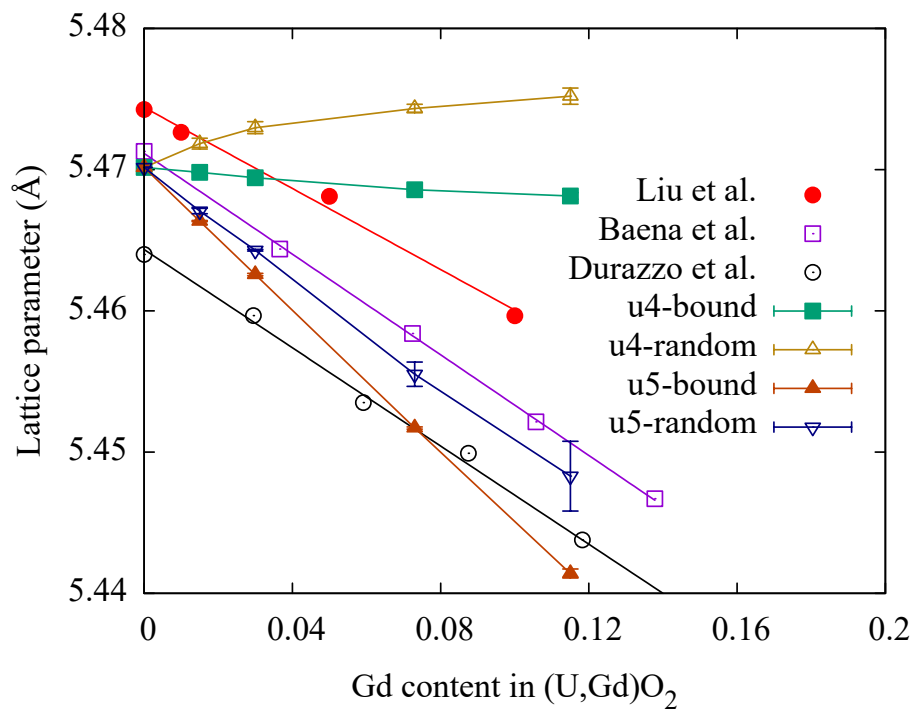

Figure 2: Lattice parameters of $\mathrm{U}_{1-x}^{4+} \mathrm{Gd}_{x} \mathrm{O}_{2-x / 2}$ or $\mathrm{U}_{1-2 x}^{4+} \mathrm{U}_{x}^{5+} \mathrm{Gd}_{x} \mathrm{O}_{2}$ as a function of $\mathrm{Gd}$ content in this work, including comparison with the reference results from Liu et al. [29], Baena et al. [30], and Durazzo et al. [31].

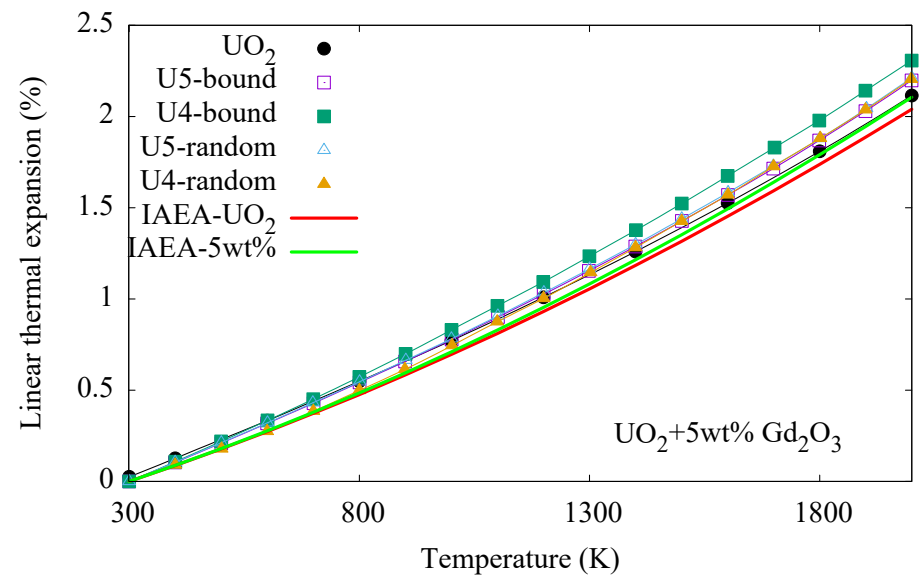

Figure 3: Linear thermal expansion $[\mathrm{L}(\mathrm{T})-\mathrm{L}(300 \mathrm{~K})] / \mathrm{L}(300 \mathrm{~K})$ of $\mathrm{UO}_{2}+5 \mathrm{wt} \% \mathrm{Gd}_{2} \mathrm{O}_{3}$ with the reference results from IAEA [32]. 


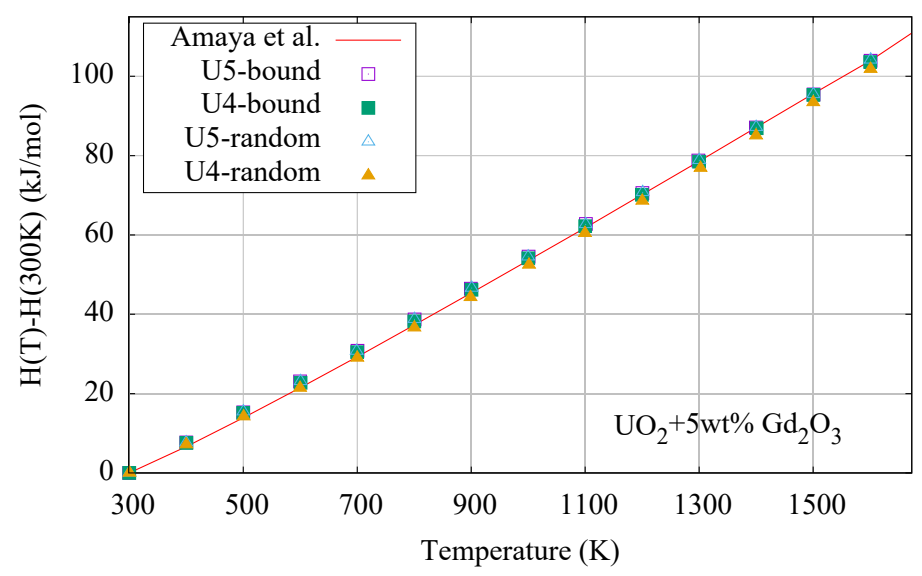

Figure 4: Change in enthalpy of $\mathrm{UO}_{2}+5 \mathrm{wt} \% \mathrm{Gd}_{2} \mathrm{O}_{3}$ with reference results from Amaya et al. [33].

et al. [34] explained that this increase in the lattice parameter was due to the size of the oxygen vacancy, which is $10 \%$ larger than that of the $\mathrm{O}^{2-}$ ion. Kim et al. [35] observed a contraction of the lattice for the hypo-stoichiometric sample, but the contraction factor (the slope of the relationship between the lattice parameter and the Gd content) is smaller than those of the hyper-stoichiometric and stoichiometric samples. The authors also explained this observation with the larger size of the oxygen vacancies. The increasing lattice parameter of U4random (no $\mathrm{U}^{5+}$ cations, only oxygen vacancies) agrees with this observation and explanation. The lattice parameter of U4-bound (no $\mathrm{U}^{5+}$ cations, only oxygen vacancies), almost constant with Gd content, may indicate smaller oxygen vacancies when bounded with Gd. However, it should be noted that the largest difference in lattice parameters (between U4-random and U5-bound with $8 \mathrm{wt} \%$ $\left.\mathrm{Gd}_{2} \mathrm{O}_{3}\right)$ is only about $0.5 \%$.

Figure 3 shows the linear thermal expansion $[\mathrm{L}(\mathrm{T})-\mathrm{L}(300 \mathrm{~K})] / \mathrm{L}(300 \mathrm{~K})$ as a function of temperature calculated for un-doped $\mathrm{UO}_{2}$ and samples with $5 \mathrm{wt} \%$ $\mathrm{Gd}_{2} \mathrm{O}_{3}$, as well as reference results from IAEA [32]. The linear expansion of the un-doped $\mathrm{UO}_{2}$ is slightly larger than the IAEA recommended data at the tem- 
perature range shown in the figure. As the original potential for un-doped $\mathrm{UO}_{2}$ was derived based on the Fink model [36] up to higher temperatures, the small difference between the calculated linear expansion and the IAEA data (about $2 \%$ at $2000 \mathrm{~K}$ ) is acceptable. It should be noted that recent experimental investigations on thermal expansion of $\mathrm{UO}_{2}[37]$ using high-energy XRD indicates 150 a thermal expansion that is systematically slightly higher than the standard reference data of Fink [36]. As such, the doped samples also show slightly larger linear expansion than the IAEA recommended data, being largest for the U4bound sample (about $10 \%$ at $2000 \mathrm{~K}$ ) and about $5 \%$ for the other three samples. Considering the uncertainties associated with the recommended data (about $4 \%$ 155 at $2000 \mathrm{~K}$ for $\mathrm{UO}_{2}$ with $\left.5 \mathrm{wt} \% \mathrm{Gd}_{2} \mathrm{O}_{3}[32]\right)$ and recent experimental data showing higher thermal expansion of $\mathrm{UO}_{2}$ [37], this difference is acceptable. Figure 4 shows the enthalpy change $\mathrm{H}(\mathrm{T})-\mathrm{H}(300 \mathrm{~K})$ as a function of temperature calculated for all samples with $5 \mathrm{wt} \% \mathrm{Gd}_{2} \mathrm{O}_{3}$ and reference results from Amaya et al. [33]. The enthalpy change shows a very small difference and is in excellent agreement with the experimental results.

It can be seen from Figures 2, 3 and 4 that the incorporation of the Gd-O potential originally developed for $\mathrm{Gd}$-doped $\mathrm{CeO}_{2}$ can predict the experimentally determined thermophysical properties of Gd-doped $\mathrm{UO}_{2}$, and thus it will be used in this work to simulate the thermal conductivity of $\mathrm{Gd}_{2} \mathrm{O}_{3}$ doped $\mathrm{UO}_{2}$.

Thermal conductivities were computed using the non-equilibrium MD (NEMD) approach of Müller-Plathe [38] as implemented in the Large-scale Atomic/Molecular Massively Parallel Simulator (LAMMPS) [39]. A heat flux was imposed along the longest direction of a $5 \times 5 \times 200$ supercell with a $5 \times 5$ unit cell crosssection. The mean temperature gradient was measured after the system had reached steady state (normally at $\sim 100 p s$ ). All simulations were calculated with periodic boundary conditions and a time-step of $1 \mathrm{fs}$. 
Table 2: Parameters for the many-body interactions described by the second term of Eq. (1) $[25,27,28]$.

\begin{tabular}{lll}
\hline \hline species & $G_{\alpha}\left(\mathrm{eV} \AA^{1.5}\right)$ & $n_{\beta}\left(\AA^{5}\right)$ \\
\hline $\mathrm{U}^{5+}$ & 1.806 & 3450.995 \\
$\mathrm{U}^{4+}$ & 1.806 & 3450.995 \\
$\mathrm{O}^{2-}$ & 0.690 & 106.856 \\
\hline \hline
\end{tabular}
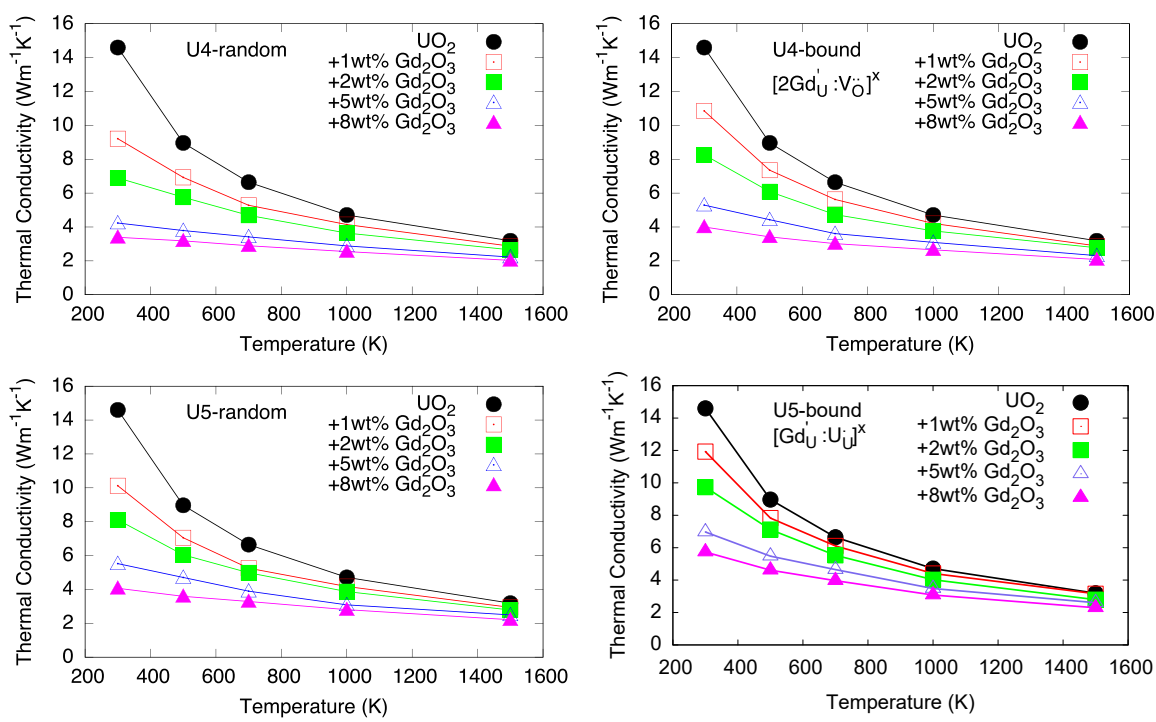

Figure 5: Temperature dependent thermal conductivity of five samples with different $\mathrm{Gd}_{2} \mathrm{O}_{3}$ contents as indicated in the figure. 


\section{Results and Discussion}

Figure 5 summarizes the calculated thermal conductivities as a function of temperature, $\mathrm{K}(\mathrm{T})$, for samples incorporating different accommodation mechanisms and for different $\mathrm{Gd}_{2} \mathrm{O}_{3}$ concentrations: $0 \mathrm{wt} \%, 1 \mathrm{wt} \%, 2 \mathrm{wt} \%, 5 \mathrm{wt} \%$ and $8 \mathrm{wt} \%$. The thermal conductivity functions $\mathrm{K}(\mathrm{T})$ are grouped into four groups according to their respective accommodation mechanism, U4-random, U4-bound, U5-random, or U5-bound, which are then shown in separate subfigures. We make the following observations and conclusions: (1) Each thermal conductivity function $\mathrm{K}(\mathrm{T})$ decreases with increasing temperature, and would seem to asymptotically approach a (lower) limit, as $\mathrm{T}$ increases. As a corollary, as $\mathrm{T}$ increases, the rate of decrease of $\mathrm{K}(\mathrm{T})$ decreases. (2) The thermal conductivity is a decreasing function of Gd content for all temperatures and all accommodation mechanisms. Consequently, the rate of decrease in $K(T)$ as $T$ increases is smaller for higher Gd contents.

To understand the effects of the Gd accommodation mechanism more clearly, we again show in Figure 6 the thermal conductivities as a function of temperature. However, this time the thermal conductivity curves $\mathrm{K}(\mathrm{T})$ are grouped according to the samples' Gd content, so that samples with the same Gd content but different Gd accommodation mechanisms are shown on the same plot. Our main observation is that at low Gd content $\left(1 \mathrm{wt} \% \mathrm{Gd}_{2} \mathrm{O}_{3}\right)$, the difference in the thermal conductivity for the different $\mathrm{Gd}$ accommodation mechanisms is relatively small, the largest difference being between U5-bound and U4-random at $300 \mathrm{~K}$ (about 23\%). However, as the Gd content increases, the difference increases (29\% and $39 \%$ between U5-bound and U4-random at $300 \mathrm{~K}$ at Gd contents of $2 \mathrm{wt} \%$ and $5 \mathrm{wt} \%$, respectively), and becomes quite distinct at a $\mathrm{Gd}$ content of $8 \mathrm{wt} \%$ (41\% between U5-bound and U4-random at 300K).

For all $\mathrm{Gd}_{2} \mathrm{O}_{3}$ concentrations, the $\mathrm{U} 5$-bound sample (i.e. $\mathrm{UO}_{2}$ containing $\left\{\mathrm{Gd}_{\mathrm{U}}^{\prime}: \mathrm{U}_{\mathrm{U}}\right\}^{\times}$defect clusters) shows the highest thermal conductivity, while the U4-random sample $\left(\mathrm{UO}_{2-x}\right.$ containing isolated $\left.\mathrm{Gd}^{3+}\right)$ shows the lowest thermal conductivity, and the thermal conductivities of $\mathrm{U} 5$-random $\left(\mathrm{UO}_{2}\right.$ containing iso- 
lated $\left.\mathrm{Gd}^{3+}\right)$ and $\mathrm{U} 4$-bound $\left(\mathrm{UO}_{2-x}\right.$ containing $\left\{2 \mathrm{Gd}_{\mathrm{U}}^{\prime}: \mathrm{V}_{\mathrm{O}}\right\}^{\times}$defect clusters) are in between and very close to each other. It can be seen from Figure 6 that samples with defect clusters (U5-bound and U4-bound) show higher thermal conductivity than those corresponding samples with isolated defects (U5random and U4-random). The U4-random and U4-bound samples $\left(\mathrm{UO}_{2-x}\right)$ contain extrinsic charge balancing oxygen vacancies due to the $\mathrm{Gd}_{2} \mathrm{O}_{3}$ doping. The oxygen vacancies are effective phonon scatterers and will reduce the thermal conductivity [13], however, the thermal conductivity of U4-bound is very close to that of U5-random (no oxygen vacancies). Thus, the defect clusters are less effective phonon scatterers and will reduce thermal conductivity degradation in $\mathrm{UO}_{2}$.

The experimental thermal conductivity data shown in Figure 6 were measured for a $\left(\mathrm{U}_{0.927} \mathrm{Gd}_{0.073}\right) \mathrm{O}_{2}$ sample of $5 \mathrm{wt} \% \mathrm{Gd}_{2} \mathrm{O}_{3}$ concentration [19]. These were thermal conductivity measurements of samples corrected to a theoretical density of $100 \% K_{t h}$, by normalising the measured thermal conductivity $K_{M}$ using the modified Loeb equation [40],

$$
K_{t h}=\frac{K_{M}}{1-P \eta}
$$

where $P(0.0443)$ is the porosity and $\eta$ an experimental parameter,

$$
\eta=2.6-5 \times 10^{-4}(T-273.15)
$$

where $T$ is the temperature in $K$, as reported by Brandt \& Neuer [10].

The oxygen-to-metal ratio $(\mathrm{O} / \mathrm{M})$ of the experimental sample was determined to be 2.000 within an experimental error of \pm 0.003 . Therefore the oxygen vacancy concentration was very low and no more than 0.15 at\%, which is negligible compared to the $\sim 7.3$ at $\%$ of $\mathrm{U}^{5+}$ ions present in the sample acting as charge compensation for $\mathrm{Gd}^{3+}$. It can be seen from Figure 6, the experimental thermal conductivity ( $5 \mathrm{wt} \% \mathrm{Gd}_{2} \mathrm{O}_{3}$ concentration) is in excellent agreement with the thermal conductivity of the U5-bound $\left(\left\{\mathrm{Gd}_{\mathrm{U}}^{\prime}: \mathrm{U}_{\mathrm{U}}\right\}^{\times}\right.$defect clusters in the $\mathrm{UO}_{2}$ ) sample. This result is in agreement with previous modelling predictions that the $\mathrm{Gd}$ is accommodated by associating itself with a $\mathrm{U}^{5+}$ cation 
to form stable defect clusters $\left\{\mathrm{Gd}_{\mathrm{U}}^{\prime}: \mathrm{U}_{\mathrm{U}}\right\}^{\times}$in $\mathrm{UO}_{2}$ with excess oxygen [7].

Thermal conductivity calculated using the FRAPCON-4.0 fuel code [41] is also shown in Figure 6 for comparison (neither burn-up nor irradiation effects were considered for a direct comparison with MD results). At low $\mathrm{Gd}_{2} \mathrm{O}_{3}$ concentrations ( $1 \mathrm{wt} \%$ and $2 \mathrm{wt} \%$ ), the thermal conductivity calculated using the FRAPCON-4.0 fuel code is slightly smaller than the MD results. As the $\mathrm{Gd}_{2} \mathrm{O}_{3}$ concentration is increased to $5 \mathrm{wt} \%$, it becomes larger than the MD results for U4-bound, U4-random and U5-random, but is consistent with the experimental results, and is very close to the MD result for U5-bound. This is even more obvious as the $\mathrm{Gd}_{2} \mathrm{O}_{3}$ concentration is increased to $8 \mathrm{wt} \%$, for which at temperatures below $\sim 700 \mathrm{~K}$, the thermal conductivity calculated using the FRAPCON-4.0 fuel code is very close to the MD result for U5-bound, but much larger than the MD results for U4-bound, U4-random and U5-random.
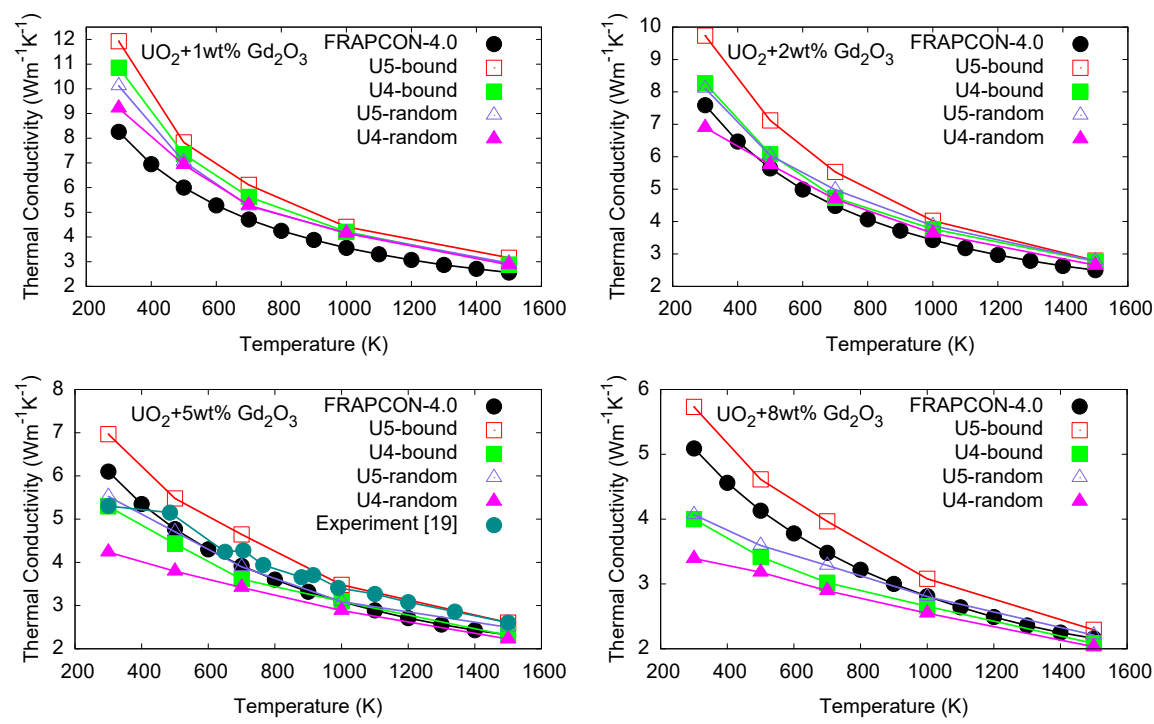

Figure 6: Temperature dependent thermal conductivity of four types of samples, representing different $\mathrm{Gd}$ accommodation mechanisms (see text for details), and with different $\mathrm{Gd}_{2} \mathrm{O}_{3}$ contents. The experimental data were obtained by scaling the measured data to the theoretical value by Hirai and Ishimoto [19]. 


\section{Summary}

The effects of Gd accommodation mechanisms and concentration on the thermal conductivity of $\mathrm{UO}_{2}$ doped with $\mathrm{Gd}_{2} \mathrm{O}_{3}$ have been investigated using molecular dynamics simulations for four types of Gd accommodation mechanisms: in $(\mathrm{U}, \mathrm{Gd}) \mathrm{O}_{2-x}$, isolated $\mathrm{Gd}^{3+}$ substitutional defects, charge compensated by isolated oxygen vacancies or $\left\{2 \mathrm{Gd}_{\mathrm{U}}^{\prime}: \mathrm{V}_{\mathrm{O}}\right\}^{\times}$defect clusters; and in (U,Gd) $\mathrm{O}_{2}$, isolated $\mathrm{Gd}^{3+}$ substitutional defects, charge compensated by $\mathrm{U}^{5+}$ or $\left\{\mathrm{Gd}_{\mathrm{U}}^{\prime}: \mathrm{U}_{\mathrm{U}}\right\}^{\times}$defect clusters. The thermal conductivity was observed to decrease systematically with increase in $\mathrm{Gd}_{2} \mathrm{O}_{3}$ concentrations and temperature. The samples with $\left\{\mathrm{Gd}_{\mathrm{U}}^{\prime}: \mathrm{U}_{\mathrm{U}}\right\}^{\times}$defect clusters show the highest thermal conductivity, while the samples with isolated $\mathrm{Gd}^{3+}$ ions forming ( $\left.\mathrm{U}, \mathrm{Gd}\right) \mathrm{O}_{2-x}$ exhibit the lowest values.

This result indicates that defect clusters are less effective phonon scatterers than their corresponding isolated defects, and would therefore result in less thermal conductivity degradation. The reduction in phonon scattering is likely due to a combination of the reduced number of scattering points (as clusters are expected to act as a single scattering point) coupled with the specific effectiveness of the scattering centre.

The experimental thermal conductivity of a $\mathrm{UO}_{2}$ sample with $5 \mathrm{wt} \% \mathrm{Gd}_{2} \mathrm{O}_{3}$ content was in good agreement with that of the sample with $\left\{\mathrm{Gd}_{\mathrm{U}}^{\prime}: \mathrm{U}_{\mathrm{U}}\right\}^{\times}$ defect clusters (U5-bound), which is consistent with previous theoretical results for the Gd accommodation mechanism of defect clusters $\left\{\mathrm{Gd}_{\mathrm{U}}^{\prime}: \mathrm{U}_{\mathrm{U}}\right\}^{\times}$in $\mathrm{UO}_{2}$ with excess oxygen.

The thermal conductivity calculated using the FRAPCON-4.0 fuel code was also in good agreement with that of the material with $\left\{\mathrm{Gd}_{\mathrm{U}}^{\prime}: \mathrm{U}_{\mathrm{U}}\right\}^{\times}$defect clusters (U5-bound) at high $\mathrm{Gd}_{2} \mathrm{O}_{3}$ concentrations.

\section{Acknowledgements}

This work was supported by the Multi-modal Australian Sciences Imaging and Visualisation Environment (MASSIVE) (www.massive.org.au) and the Sci- 
entific Computing team at ANSTO.

\section{References}

[1] S. C. Middleburgh, D. C. Parfitt, P. R. Blair, R. W. Grimes, Atomic scale modeling of point defects in zirconium diboride, Journal of the American Ceramic Society 94 (7) (2011) 2225-2229.

[2] V. Barchevtsev, V. Artisyuk, H. Ninokata, Concept of erbium doped uranium oxide fuel cycle in light water reactors, Journal of Nuclear Science and Technology 39 (5) (2002) 506-513.

[3] H. Riella, M. Durazzo, M. Hirata, R. Nogueira, $\mathrm{UO}_{2}-\mathrm{Gd}_{2} \mathrm{O}_{3}$ solid solution formation from wet and dry processes, Journal of Nuclear Materials 178 (2) (1991) $204-211$.

[4] M. Hirai, J. Davies, R. Williamson, Diffusivities of fission gas species in $\mathrm{UO}_{2}$ and $(\mathrm{U}, \mathrm{Gd}) \mathrm{O}_{2}$ nuclear fuels during irradiation, Journal of nuclear materials 226 (1-2) (1995) 238-251.

[5] K. W. Song, K. S. Kim, J. H. Yang, K. W. Kang, Y. H. Jung, A mechanism for the sintered density decrease of $\mathrm{UO}_{2}-\mathrm{Gd}_{2} \mathrm{O}_{3}$ pellets under an oxidizing atmosphere, Journal of nuclear materials 288 (2) (2001) 92-99.

[6] S. C. Middleburgh, D. C. Parfitt, R. W. Grimes, B. Dorado, M. Bertolus, P. R. Blair, L. Hallstadius, K. Backman, Solution of trivalent cations into uranium dioxide, Journal of Nuclear Materials 420 (1) (2012) 258-261.

[7] S. C. Middleburgh, R. W. Grimes, K. H. Desai, P. R. Blair, L. Hallstadius, K. Backman, P. V. Uffelen, Swelling due to fission products and additives dissolved within the uranium dioxide lattice, Journal of Nuclear Materials 427 (1-3) (2012) $359-363$.

[8] C. Ronchi, M. Sheindlin, M. Musella, G. J. Hyland, Thermal conductivity of uranium dioxide up to $2900 \mathrm{k}$ from simultaneous measurement of the 
heat capacity and thermal diffusivity, Journal of Applied Physics 85 (2) (1999) 776-789.

[9] S. R. Phillpot, A. El-Azab, A. Chernatynskiy, J. S. Tulenko, Thermal Conductivity of $\mathrm{UO}_{2}$ Fuel: Predicting Fuel Performance from Simulation, JOM 63 (8) (2011) 77-83.

[10] R. Brandt, G. Neuer, Thermal conductivity and thermal radiation properties of $\mathrm{UO}_{2}$, J. Non-Equilib. Thermodyn. 1 (1976) 3-23.

[11] P. Lindan, M. Gillan, A molecular dynamics study of the thermal conductivity of $\mathrm{CaF}_{2}$ and $\mathrm{UO}_{2}$, Journal of Physics: Condensed Matter 3 (22) (1991) 3929 .

[12] K. Gofryk, S. Du, C. Stanek, J. Lashley, X.-Y. Liu, R. Schulze, J. Smith, D. Safarik, D. Byler, K. McClellan, et al., Anisotropic thermal conductivity in uranium dioxide, Nature communications 5 (2014) 4551.

[13] M. J. Qin, M. W. D. Cooper, E. Y. Kuo, M. J. D. Rushton, R. W. Grimes, G. R. Lumpkin, S. C. Middleburgh, Thermal conductivity and energetic recoils in $\mathrm{UO}_{2}$ using a many-body potential model, Journal of Physics: Condensed Matter 26 (49) (2014) 495401.

[14] M. L. Fullarton, M. J. Qin, M. Robinson, N. A. Marks, D. J. M. King, E. Y. Kuo, G. R. Lumpkin, S. C. Middleburgh, Structure, properties and formation of $\mathrm{PuCrO}_{3}$ and $\mathrm{PuAlO}_{3}$ of relevance to doped nuclear fuels, Journal of Materials Chemistry A 1 (46) (2013) 14633-14640.

[15] T. Yamada, H. Matsuda, M. Yoshimura, Melting and Measurements of Solidification Point of $\mathrm{UO}_{2}-\mathrm{Gd}_{2} \mathrm{O}_{3}$ Solid Solutions Under Solar Furnace, JOURNAL-HIGH TEMPERATURE SOCIETY 25 (1999) 71-79.

[16] M. Amaya, M. Hirai, H. Sakurai, K. Ito, M. Sasaki, T. Nomata, K. Kamimura, R. Iwasaki, Thermal conductivities of irradiated $\mathrm{UO}_{2}$ and (U, Gd) $\mathrm{O}_{2}$ pellets, Journal of Nuclear Materials 300 (1) (2002) 57-64. 
[17] M. Amaya, M. Hirai, T. Kubo, Y. Korei, Thermal conductivity measurements on $10 \mathrm{wt} \% \mathrm{Gd}_{2} \mathrm{O}_{3}$ doped $\mathrm{UO}_{2+x}$, Journal of nuclear materials 231 (1) (1996) 29-33.

[18] M. Amaya, M. Hirai, The effects of oxidation on the thermal conductivity of $(\mathrm{U}, \mathrm{M}) \mathrm{O}_{2}$ pellets $(\mathrm{M}=\mathrm{Gd}$ and/or simulated soluble FPs), Journal of nuclear materials 246 (2-3) (1997) 158-164.

[19] M. Hirai, S. Ishimoto, Thermal diffusivities and thermal conductivities of $\mathrm{UO}_{2}-\mathrm{Gd}_{2} \mathrm{O}_{3}$, Journal of Nuclear Science and Technology 28 (11) (1991) 995-1000.

[20] S. Ishimoto, M. Hirai, K. Ito, Y. Korei, Effects of soluble fission products on thermal conductivities of nuclear fuel pellets, Journal of Nuclear Science and Technology 31 (8) (1994) 796-802.

[21] K. Iwasaki, T. Matsui, K. Yanai, R. Yuda, Y. Arita, T. Nagasaki, N. Yokoyama, I. Tokura, K. Une, K. K. HARADA, Effect of $\mathrm{Gd}_{2} \mathrm{O}_{3}$ Dispersion on the Thermal Conductivity of $\mathrm{UO}_{2}$, Journal of Nuclear Science and Technology 46 (7) (2009) 673-676.

340 [22] S. Fukushima, T. Ohmichi, A. Maeda, H. Watanabe, The effect of gadolinium content on the thermal conductivity of near-stoichiometric ( $\mathrm{U}, \mathrm{Gd}) \mathrm{O}_{2}$ solid solutions, Journal of Nuclear Materials 105 (2-3) (1982) 201-210.

[23] K. Minato, T. Shiratori, H. Serizawa, K. Hayashi, K. Une, K. Nogita, M. Hirai, M. Amaya, Thermal conductivities of irradiated $\mathrm{UO}_{2}$ and (U, Gd) $\mathrm{O}_{2}$, Journal of nuclear materials 288 (1) (2001) 57-65.

[24] F. Bruneval, M. Freyss, J.-P. Crocombette, Lattice constant in nonstoichiometric uranium dioxide from first principles, Phys. Rev. Materials 2 (2018) 023801 .

[25] M. W. D. Cooper, M. J. D. Rushton, R. W. Grimes, A many-body potential approach to modelling the thermomechanical properties of actinide oxides, Journal of Physics: Condensed Matter 26 (10) (2014) 105401. 
[26] M. Rushton, A. Chroneos, Impact of uniaxial strain and doping on oxygen diffusion in $\mathrm{CeO}_{2}$, Scientific reports 4 (1) (2014) 6068 .

[27] X.-Y. Liu, M. W. D. Cooper, K. J. McClellan, J. C. Lashley, D. D. Byler, B. D. C. Bell, R. W. Grimes, C. R. Stanek, D. A. Andersson, Molecular Dynamics Simulation of Thermal Transport in $\mathrm{UO}_{2}$ Containing Uranium, Oxygen, and Fission-product Defects, Phys. Rev. Applied 6 (2016) 044015.

[28] X.-Y. Liu, M. W. D. Cooper, K. J. McClellan, J. C. Lashley, D. D. Byler, B. D. C. Bell, R. W. Grimes, C. R. Stanek, D. A. Andersson, Erratum: Molecular Dynamics Simulation of Thermal Transport in $\mathrm{UO}_{2}$ Containing Uranium, Oxygen, and Fission-Product Defects [Phys. Rev. Applied 6, 044015 (2016)], Phys. Rev. Applied 7 (2017) 059901.

[29] N. Liu, J. Kim, J. Lee, Y.-S. Youn, J.-G. Kim, J.-Y. Kim, J. J. Noël, D. W. Shoesmith, Influence of gd doping on the structure and electrochemical behavior of uo2, Electrochimica Acta 247 (2017) 496 - 504.

[30] A. Baena, T. Cardinaels, K. Govers, J. Pakarinen, K. Binnemans, M. Verwerft, Lattice contraction and lattice deformation of $\mathrm{UO}_{2}$ and $\mathrm{ThO}_{2}$ doped with $\mathrm{Gd}_{2} \mathrm{O}_{3}$, Journal of Nuclear Materials 467 (2015) 135 - 143.

[31] M. Durazzo, F. Oliveira, E. U. de Carvalho, H. Riella, Phase studies in the $\mathrm{UO}_{2}-\mathrm{Gd}_{2} \mathrm{O}_{3}$ system, Journal of Nuclear Materials 400 (3) (2010) $183-188$.

[32] IAEA, Thermophysical properties database of materials for light water reactors and heavy water reactors final report of a coordinated research project 1999-2005, Report 1011-4289 92-0-104706-1 (2006).

[33] M. AMAYA, K. UNE, M. HIRAI, Heat Capacity Measurements of $\mathrm{U}_{1-y} \mathrm{Gd}_{y} \mathrm{O}_{2}(\mathrm{y}=0-0.27)$ from 325 to $1,673 \mathrm{~K}$, Journal of Nuclear Science and Technology 41 (2) (2004) 108-115.

[34] T. Ohmichi, S. Fukushima, A. Maeda, H. Watanabe, On the relation between lattice parameter and $\mathrm{O} / \mathrm{M}$ ratio for uranium dioxide-trivalent rare 
earth oxide solid solution, Journal of Nuclear Materials 102 (1) (1981) 40 -46 .

[35] J. Kim, J. Lee, Y.-S. Youn, N. Liu, J.-G. Kim, Y.-K. Ha, S.-E. Bae, D. W. Shoesmith, J.-Y. Kim, The combined influence of gadolinium doping and non-stoichiometry on the structural and electrochemical properties of uranium dioxide, Electrochimica Acta 247 (2017) 942 - 948.

385 [36] J. Fink, Thermophysical properties of uranium dioxide, Journal of Nuclear Materials 279 (1) (2000) $1-18$.

[37] M. Guthrie, C. Benmore, L. Skinner, O. Alderman, J. Weber, J. Parise, M. Williamson, Thermal expansion in $\mathrm{UO}_{2}$ determined by high-energy Xray diffraction, Journal of Nuclear Materials 479 (2016) $19-22$.

[38] F. Müller-Plathe, A simple nonequilibrium molecular dynamics method for calculating the thermal conductivity, The Journal of Chemical Physics 106 (14) (1997) 6082-6085.

[39] S. Plimpton, Fast parallel algorithms for short-range molecular dynamics, Journal of Computational Physics 117 (1) (1995) 1 - 19.

395 [40] A. L. Loeb, Thermal conductivity: Viii, a theory of thermal conductivity of porous materials, Journal of the American Ceramic Society 37 (2) (1954) 96-99.

[41] K. J. Geelhood, W. G. Luscher, P. A. Raynaud, I. E. Porter, FRAPCON4.0: A computer Code for the Calculation of Steady-State, ThermalMechanical Behavior of Oxide Fuel Rods for High Burnup, Pacific Northwest National Laboratory, pnnl-19418, vol.1 rev.2 Edition (September 2015). 